\title{
Inventario cultural tangible e intangible del cantón La Maná provincia de Cotopaxi año 2020
}

\begin{abstract}
Tangible and intangible cultural inventory of La Maná canton, Cotopaxi Province year 2020
\end{abstract}

Laura Melisa Castillo Oviedo. ${ }^{1}$, Mishel del Rocio Chango Tenelema. ${ }^{2}$, Natalia Geoconda Zambrano Cuadro. ${ }^{3}$

\section{Recibido: 11-10-2020 / Revisado: 12-11-2020 /Aceptado: 08-12-2020/ Publicado: 02-01-2021}

\begin{abstract}
.
DOI: https://doi.org/10.33262/cienciadigital.v5i1.1517
\end{abstract}

Introduction. The cultural inventory is a tool that is very useful to identify, register and display the movable and immovable property of the canton and its different parishes, at the same time, it is committed to promoting the understanding and social appropriation of the country's cultural heritage, and committing to improve the social capacity for the correct management of wealth. Objective. Prepare a tangible and intangible cultural inventory of the canton, in order to contribute to local development. Methodology. The present study was carried out in the canton of La Maná, where an information survey was developed using the following methods: qualitative, historical, descriptive and synthetic method, which helped to collect concrete and precise information, therefore, the bibliographic research, on-site visits and, the methodology of the National Institute of Cultural Heritage was also used, the field work for the collection of information was carried out in October 2020 with a duration of 30 days during which interviews were conducted with the inhabitants, tourists and representatives of the parishes. Results. The results show us that $86 \%$ of those surveyed consider it feasible to draw up a tangible and intangible cultural inventory of La Maná canton, having a total of 58 cultural manifestations within the canton. Conclusion. The collection of information in the field of all the tangible and intangible assets that exist in the La Maná canton was analyzed, it was found that the longest-lived people in each parish are those who carry all the knowledge of the history and culture that they represent in each This is important since it is expected to continue to spread in current and future generations due to the fact that these

\footnotetext{
${ }^{1}$ Universidad Técnica de Cotopaxi Extensión La Maná, Ingeniería en Ecoturismo, La Maná - Ecuador., laura.castillo9978@utc.edu.ec, https://orcid.org/0000-0003-0506-5615

2 Universidad Técnica de Cotopaxi Extensión La Maná, Ingeniería en Ecoturismo, La Maná - Ecuador., mishel.chango6273@utc.edu.ec, https://orcid.org/0000-0002-9141-6858

${ }^{3}$ Universidad Técnica de Cotopaxi Extensión La Maná, Ingeniería en Ecoturismo, La Maná - Ecuador., natalia.zambrano@utc.edu.ec https://orcid.org/0000-0002-5678-7725
} 
strengths can be used as an entrance to the canton's economy, increasing visitors who love culture.

Keywords: Inventory, assets, tangible, intangible, cultural heritage.

\section{Resumen.}

Introducción. El inventario cultural es una herramienta que tiene una gran utilidad para identificar, registrar y exhibir los bienes muebles e inmuebles del cantón y de sus diferentes parroquias, al mismo tiempo, se compromete a promover la comprensión y la apropiación social del patrimonio cultural del país, y comprometiéndose a mejorar la capacidad social para la correcta gestión del patrimonio. Objetivo. Elaborar un inventario cultural tangible e intangible del cantón, con la finalidad de aportar al desarrollo local. Metodología. El presente estudio se llevó a cabo en el cantón la Maná, donde se desarrolló un levantamiento de información utilizando los siguientes métodos: método cualitativo, histórico, descriptivo y sintético los cuales ayudaron a recabar la información concreta y precisa, por ende, se utilizó la investigación bibliográfica, visitas in situ y, se empleó también la metodología del Instituto Nacional del Patrimonio Cultural, el trabajo de campo para la recolección de la información se ejecutó en octubre del 2020 con una duración de 30 días durante los cuales se realizó entrevistas a los habitantes, turistas y representantes de las parroquias. Resultados. Los resultados nos reflejan que el $86 \%$ de las encuestados, ven factible la elaboración de un inventario cultural tangible e intangible del cantón La Maná, teniendo, un total de 58 manifestaciones culturales dentro del cantón. Conclusión. Se analizó la recopilación de información en campo de todos los bienes tangibles e intangibles que existen en el cantón La Maná, se constató que las personas más longevas de cada parroquia son las que llevan todos los conocimientos de la historia y la cultura que representa en cada zona, esto es importante ya que se espera que se siga difundiendo en las generaciones actuales y futuras por el hecho que se puede aprovechar estas fortalezas como una entrada a la economía del cantón, incrementando visitantes amantes a la cultura.

Palabras claves: Inventario, bienes, tangible, intangible, patrimonio cultural.

\section{Introducción.}

La Cultura a través de la historia, siempre ha estado presente en la vida diaria de las personas, hoy en día estos campos se presentan como una gran oportunidad de apoyar al desarrollo de pueblos y naciones, su gestión integral basada en herramientas administrativas y tecnológicas actuales, se conjugan con conocimientos ancestrales logrando con esta simbiosis, que estas áreas alguna vez olvidadas, sean actualmente potenciales en el desarrollo de los territorios como parroquias y el municipio, contribuyendo con esto a la búsqueda constante del buen vivir de sus ciudadanos.

Según la UNESCO (2019) En el mundo interconectado en el que vivimos, es fácil constatar que la cultura tiene el poder de transformar las sociedades. Sus diversas manifestaciones, que abarcan desde los más preciados monumentos históricos y museos hasta los ritos tradicionales y el arte contemporáneo, enriquecen nuestro día a día de múltiples maneras. (UNESCO, 2019) 
De acuerdo a la UNESCO (2001) con la Declaración Universal sobre la Diversidad Cultural de la UNESCO, la cultura debe ser considerada como el conjunto de rasgos distintivos espirituales y materiales, intelectuales y afectivos que caracterizan a una sociedad o a un grupo social y que abarca, además de las artes y las letras, los modos de vida, las maneras de vivir juntos, los sistemas de valores, las tradiciones y las creencias. Sin embargo, no podemos dejar de mencionar la cultura popular considerada como conjunto de patrones culturales y manifestaciones artísticas y literarias creadas o consumidas preferentemente por las clases populares sin instrucción académica, pero con un compendio de manifestaciones artísticas y folklóricas que emana directamente del pueblo, y está arraigada en las tradiciones, valores y creencias de la gente, y ha sido trasmitida de generación en generación por décadas o incluso siglos. (Reinoso, 2019).

(Camelo, 2013) Nos comparte que, los inventarios de patrimonio cultural son una herramienta para identificar, documentar y visibilizar los bienes y manifestaciones culturales propios de las comunidades y colectividades. A su vez busca facilitar el conocimiento y la apropiación social del patrimonio cultural de la Nación y contribuye a fortalecer la capacidad social de gestión del patrimonio de las comunidades locales y a orientar la toma de decisiones de política pública. El Programa Nacional de Inventario de Patrimonio Cultural se encarga de coordinar los procesos de identificación, documentación valoración del patrimonio cultural y el registro de los bienes culturales muebles e inmuebles del país, como fuente de información para la definición de acciones dirigidas a su manejo y protección.

Ecuador cuenta con una diversidad magnifica de culturas, regiones como la costa, sierra, oriente y amazonia, es por eso que alberga un sin número de etnias como afro ecuatorianos, mestizos, indígenas y blancos este patrimonio se ha compartido con el mundo en la industria del turismo al acoger en su territorio a pueblos milenarios, cuyas costumbres, tradiciones y cosmovisiones han sobrevivido al paso del tiempo.

Nuestro país con rasgos profundos traducidos en fiestas, ritos, costumbres, formas de vida con una inmensa riqueza de expresiones de arte popular de un colorido extraordinario, pasando por los sistemas de creencias, formas de trabajo, vestimenta, hasta una variada cocina con productos locales que ha merecido que la Casa de la Cultura Núcleo de Cotopaxi, recoja todo este bagaje desbordante de manifestaciones que mantiene vivo el legado de nuestras culturas milenarias (Reinoso, 2019).

Salvaguardar la cultura tangible e intangible como las tradiciones y expresiones orales, artes del espectáculo, usos sociales, rituales y actos festivos, conocimientos y usos relacionados con la naturaleza y el universo y técnicas artesanales tradicionales del cantón, con la finalidad de fortalecer los atractivos turísticos culturales, se puede considerar el rescate como una estrategia de valorización de tesoros espirituales que unen a los miembros de la comunidad. Los saberes de los pueblos originarios, tradicionales y populares, son cuantiosos. Sin embargo, al no ser divulgados y su falta continua de trasmisión a causa de diferentes factores sociales, ambientales, políticos etc. 
Con el pasar de los años se puede ir perdiendo el valor inigualable del patrimonio tangible e intangible.

Según (Alarcón, 1996), Existen leyendas de que estas tierras fueron habitadas por los colorados y cayapas, que parecen ser confirmadas con las siguientes apariciones; topónimos existentes en este sector de Cotopaxi, al igual que en los ríos Manabí, como son los nombres de los ríos: Calabí, yuyunví, uinví. Al pasar por las estribaciones de los Andes occidentales de Cotopaxi, encontraron vestigios asentamientos y sembríos de colorados, al igual que las versiones de los primeros moradores o dueños de estas tierras sobre la fiesta anual de estas tribus que avanzaban desde el norte, actual Santo Domingo de los Colorados, hasta Calope y Chipe actual cantón La Maná.

En este contexto, este artículo presenta el resultado de la elaboración del inventario cultural, respondiendo a la necesidad del levantamiento, actualización de información adecuada para los habitantes y turistas de la localidad, junto con el GAD Municipal del cantón y juntas parroquiales, ven al turismo como una oportunidad para mejorar las condiciones de vida, siempre teniendo en cuenta eje de la sostenibilidad.

El objetivo del presente estudio es elaborar un inventario cultural tangible e intangible del cantón La Maná, provincia de Cotopaxi año 2020, con la finalidad de aportar al desarrollo local con la información recopilada de los bienes culturales de las parroquias urbanas y rurales, por otra parte se establecerán los bienes culturales según sus ámbitos y sub ámbitos respecto al instructivo para fichas de registro e inventario del patrimonio cultural, con la interpretación de los resultados de las encuestas aplicadas, considerando así la importancia de realizar el inventario cultural de bienes muebles e inmuebles del cantón.

\section{Metodología.}

El presente estudio se llevó a cabo en el cantón la Maná las cuales alberga sus 5 parroquias que conforman Guasaganda, Pucayacu, El Carmen, El Triunfo y La Maná, se desarrolló un levantamiento de información utilizando el método cualitativo que conforma las fuetes primarias como lo son las entrevistas, que se las aplicó a personas claves del cantón, como también se tuvo el apoyo de los presidentes parroquiales entre otras personas que representan a la historia de La Maná, por ende, se utilizó fuentes secundarias como libros, redes sociales, Instructivo para fichas de registro e inventario del patrimonio cultural respecto al Instituto Nacional de Patrimonio Cultural, sitios web de los GAD parroquiales de Pucayacu, Guasaganda y del GAD Municipal La Maná.

La etapa de la recolección de datos tuvo lugar en octubre del 2020, con una duración de 30 días durante los cuales se realizó entrevistas a los habitantes y representantes de las parroquias tomando todas las medidas de bioseguridad como nos indica el protocolo general de bioseguridad para la prevención del Covid-19. 
Dentro de nuestra investigación indagamos información bibliográfica y visitas in situ donde se recopilo información primaria que consiste en encuestas, entrevistas, observación, fichas de los diferentes ámbitos culturales que posee el INPC y se recopilo información de fuentes secundarias acerca de los bienes muebles e inmuebles como en: periódicos digitales, libros, artículos científicos, tesis, revistas, páginas web como el Gobierno Autónomo Descentralizado Municipal de La Maná, GADs parroquiales, Ministerio de Cultura, Instituto Nacional de Patrimonio Cultural y la UNESCO.

Investigación de Campo, mediante este estudio se obtuvo datos evidentes de las principales manifestaciones culturales existentes en las parroquias del cantón teniendo en cuenta la gastronomía local, esta información se alcanzó a obtener por medio de la aplicación de entrevistas a las personas encargadas de los GADs parroquiales, GAD Municipal o por medio de la población en general, logrando la indagación usual, colocando toda la información general en su respetivo instructivo para fichas de registro e inventario de acuerdo a cada ámbito y subámbito del patrimonio cultural inmaterial.

De acuerdo a la metodología del INPC, (2011) "Esta herramienta fue de gran importancia para la investigación, gracias a sus directrices se pudo realizar el correcto levantamiento de información para poder llenar cada paso de las fichas de registro para posteriormente subirlas en el sistema de información del patrimonio cultural ecuatoriano" (SIPCE) (INPC, 2011).

Tipos de métodos para el desarrollo de la investigación se emplearon varios métodos como histórico, descriptivo y sintético los cuales ayudaron a recabar información.

(Marias, 1949) Nos manifiesta que el método histórico contiene por objeto escribir la historia, es decir, producir la histografia para establecer los acontecimientos de la forma más objetiva posible. Ayudo a verificar datos e historia que se han planteado en libros, páginas web de los diferentes GADs a través de la reconstrucción del pasado de manera más exacta, estos acontecimientos sobrellevaron a base de entrevistas a los primeros moradores de cada una de las parroquias del Cantón teniendo a si la información valiosa y fructífera.

(Marroquín, 2012) Nos indica que "El método descriptivo se basa en la observación, por lo que son de gran importancia los cuatro factores psicológicos: atención, sensación, percepción y reflexión".

Mediante este se describe el estado en que se encuentra los bienes tangibles e intangibles estableciendo los datos de la localización, coordenadas, fotografías, denominación, ámbito y subámbito, información explicita del bien por lo general describiendo la reseña y la manifestación de los mismos, adjuntándolo todo en una ficha técnica. 
Método Sintético es un proceso de análisis de razonamiento que busca la forma de contribuir un acontecimiento de manera resumida, valiéndose de los diferentes elementos fundamentales que estuvieron presentes en el desarrollo del acontecimiento (Pacheco, 2019).

Se utilizó para interpretar la información recabada en entrevistas aplicadas en el cantón a con el fin de obtener información primaria acerca de las manifestaciones culturales a través de fichas técnicas.

En base al (PDOT, 2015 - 2020), del Cantón Maná se tomó el total de la población es 43.035 habitantes que aplicando la fórmula de la proyección $43.035 *(1+1,66 \%) \wedge 1$ hasta el año 2020 existe 53.242 habitantes.

Para sacar el tamaño de la muestra según Murray y Larry (2005) nos presenta la siguiente formula:

$\mathrm{N}=$ Tamaño de la localidad.

$\mathrm{Z}=$ Valor conveniente a la distribución $\mathrm{Za}=1.96^{\wedge} 2$

$\mathrm{p}=$ Prevalencia esperada del parámetro a evaluar, en caso de desconocerse $(\mathrm{p}=0.5)$

$\mathrm{q}=1-\mathrm{p}(0,95)$

$\mathrm{d}=$ Precisión $5 \%$

$$
\begin{gathered}
n=\frac{N * Z a \wedge 2 * p * q}{d \wedge 2(N-1)+Z a \wedge 2 * p * q} \\
n=\frac{53242 *(1,96) \wedge 2 * 0,05 * 0,95}{(0,05) \wedge 2 *(53242-1)+(1,96) \wedge 2 * 0,05 * 0,95} \\
n=\frac{9556,797}{131,1122}
\end{gathered}
$$

Encuestas aplicar $=73$

\section{Resultados.}

La presente investigación muestra los resultados obtenidos del estudio que se realizó para la elaboración del inventario cultural tangible e intangible del cantón La Maná provincia de Cotopaxi, tomando en cuenta que cada una de las parroquias que conforma el cantón tiene una inmensa riqueza, en su historia, leyendas, gastronomía, artesanía, festividades y arqueología. 
Sin embargo, las parroquias enfrentan factores como el desempleo, la migración, pérdida de la identidad cultural, desvalorización del patrimonio, también teniendo un alto grado de analfabetismo entre otros factores que conlleva a la incidencia negativa en su desarrollo.

Para ayudar a superar esta problemática se realizó el correcto levantamiento de información de la parte cultural tangible como es la gastronomía, artesanía y la arqueología existente, para lograr que la comunidad y sus visitantes conozca la diversidad de bienes culturales que se puede dar dentro de cada uno de las localidades, también cuenta la parte intangible como son las leyendas, historia, relatos, música y danza que conlleva la recuperación de esta información que es importante conservar para motivar a las personas a valorar cada uno de estos ámbitos que representa una zona.

Con el apoyo del GAD Municipal La Maná, principalmente el área de Jefatura de cultura y patrimonio nos permitió realizar la actualización correcta al sistema "SIPCE que es una plataforma informática y donde es utilizada para realizar consultas, elaboraciones estadísticas y estos documentos ayudan para que el turista interesado busque información importante acerca de los bienes muebles e inmuebles del sitio que quiera visitar" (INPC, s.f.).

\section{Provincia a la que proviene.}

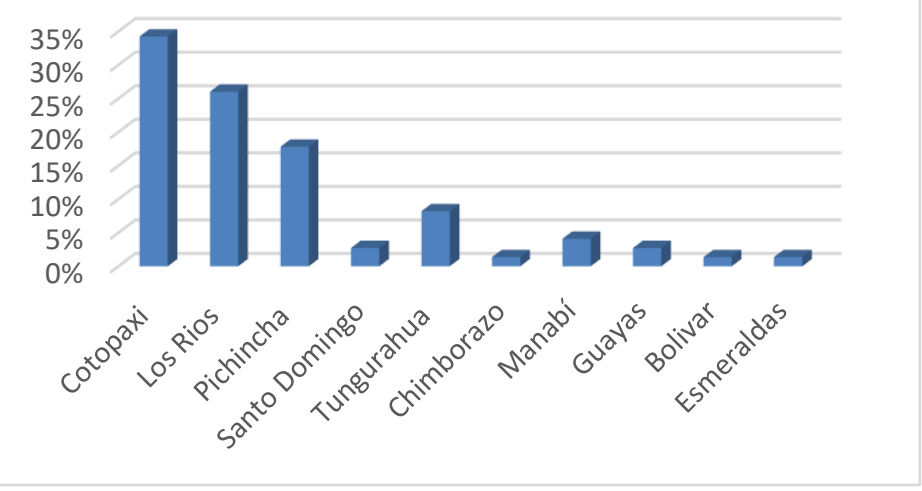

Figura 1: Provincia a la que proviene.

Fuente: Grupo de trabajo, 2020.

Según los resultados obtenidos de las 73 encuesta que se realizó a los habitantes del cantón y a sus visitantes pudimos constatar que la mayor parte pertenece a la provincia de Cotopaxi con un total de $34 \%$, como segundo lugar tenemos la provincia de Los Ríos con el $26 \%$, en tercer lugar la provincia de Pichincha con el 13\%, en cuarto lugar la provincia de Tungurahua con el $8 \%$, quinto lugar la provincia de Manabí con el $4 \%$, en sexto y séptimo lugar a las provincias de Santo Domingo y Guayas con el 3\%, octavo, noveno y décimo lugar las provincias de Chimborazo, Bolívar y Esmeraldas con el $1 \%$. 
2. Elaboración del inventario Cultural.

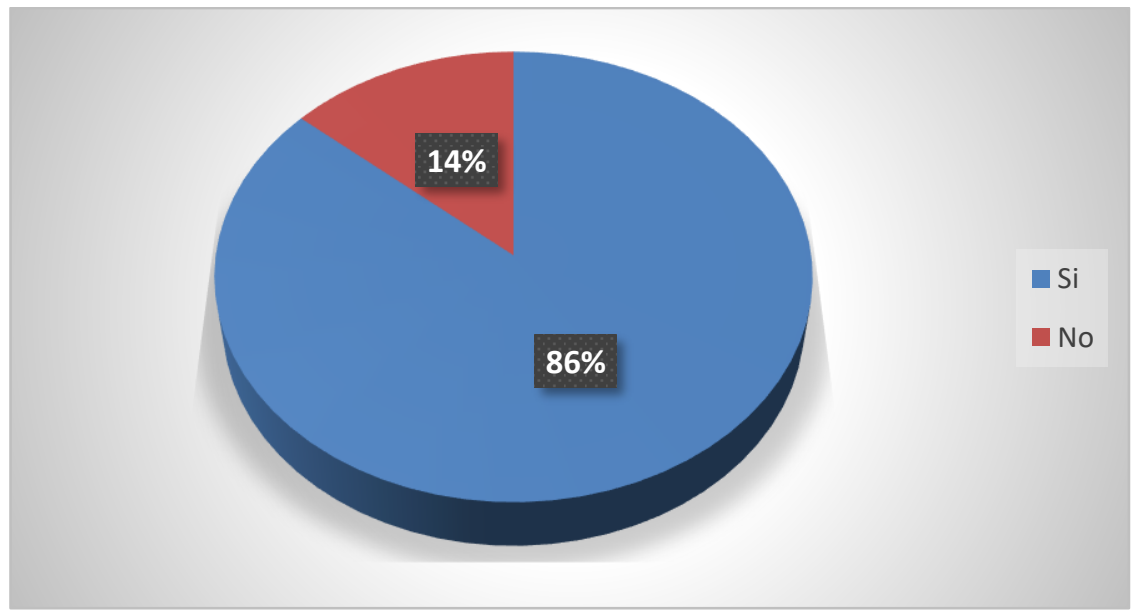

Figura 2: Elaboración del Inventario Cultural.

Fuente: Grupo de trabajo, 2020.

Se analiza que el $86 \%$ del resultado de la encuesta nos dice que es factible la elaboración de un inventario cultural del cantón La Maná ya que es importante que todas las personas conozcan los bienes tangibles e intangible que existen en un zona o localidad, para el conocimiento mismo sobre la cultura significativa que se ha venido trascendiendo hace mucho tiempo atrás.

\section{Fomentar el turismo.}

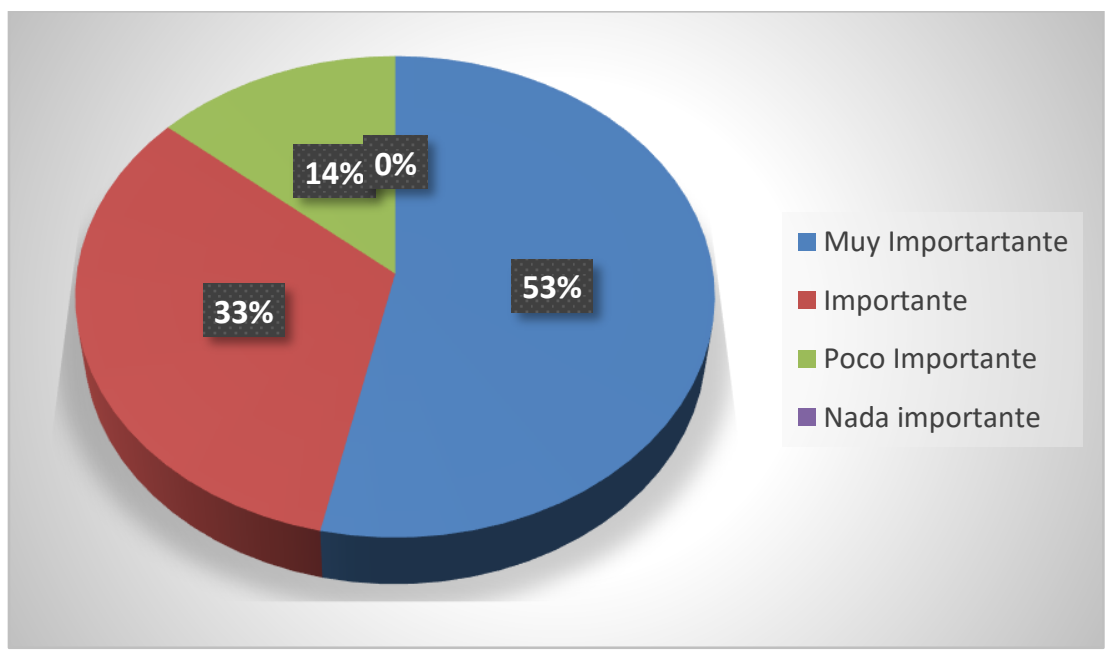

Figura 3: Fomentar el turismo.

Fuente: Grupo de trabajo, 2020.

El $53 \%$ del resultado alcanzado es considerado importante fomentar del turismo a través de un inventario, ya que en este caso la mayor información posible y sustancial es ubicado en el contenido de cada bien que conforma un inventario, con el objetivo que las personas oriundas y visitantes se informen de la cultura que sobresale en el cantón La Maná.

Tabla $N^{\circ} 1$ : Inventario Cultural. 
www.cienciadigital.org

Vol. 5, $\mathrm{N}^{\circ} 1$, p. 30-50, Enero - Marzo, 2021

\begin{tabular}{|c|c|c|c|c|}
\hline Denominación & Tipo & Sub tipo & Parroquia & Descripción \\
\hline Agua Vital & $\begin{array}{c}\text { Manifestaciones } \\
\text { Religiosas y } \\
\text { Creencias } \\
\text { Populares }\end{array}$ & Literatura & La Maná & $\begin{array}{l}\text { El agua de las vertientes del cantón La Maná } \\
\text { contiene una carga energética muy alta debido a } \\
\text { la presencia de minerales como la plata y el oro. } \\
\text { Ésas vertientes pueden localizarse en las } \\
\text { montañas que rodean a la población de la Maná. } \\
\text { En las montañas existen vertientes buenas, es el } \\
\text { agua más pura en el mundo. }\end{array}$ \\
\hline
\end{tabular}

Figura 1. Agua Vital.

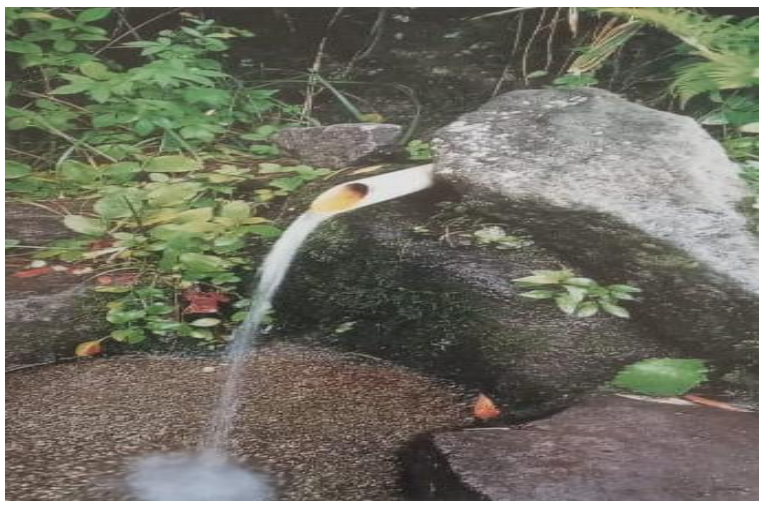

Fuente: (Messages from wáter, 2002)

\begin{tabular}{|c|c|c|c|c|}
\hline $\begin{array}{c}\text { Artesanía Tejido } \\
\text { de Atarraya }\end{array}$ & $\begin{array}{c}\text { Técnica } \\
\text { Artesanal } \\
\text { Tradicional }\end{array}$ & Tejidos & La Maná & $\begin{array}{l}\text { Esta actividad del tejido de atarraya se la realiza } \\
\text { más de 50 años en el cantón por el Sr. Ángel } \\
\text { Llanos, realiza trabajos completos y como } \\
\text { también hace arreglos en caso de estar dañadas. }\end{array}$ \\
\hline
\end{tabular}

Figura 2. Atarraya.

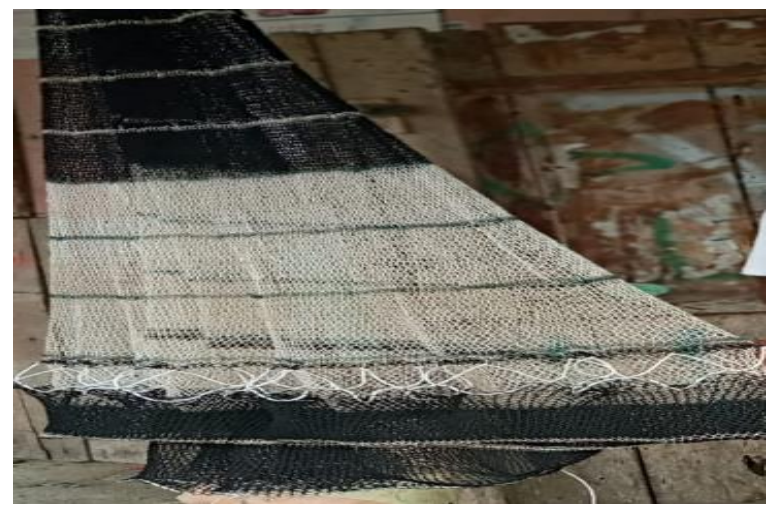

Fuente: (Castillo Laura, 2020) 
Tabla $N^{\circ}$ 2: Inventario Cultural.

\begin{tabular}{|c|c|c|c|c|}
\hline Denominación & Tipo & Sub tipo & Parroquia & $\mathbf{D}$ \\
\hline $\begin{array}{l}\text { Estofado de } \\
\text { Campeche }\end{array}$ & Gastronomía & $\begin{array}{l}\text { Platos } \\
\text { Típicos }\end{array}$ & La Maná & $\begin{array}{l}\text { El río San Pablo a } \\
\text { peces que sirven de } \\
\text { del cantón La Mar } \\
\text { vida se puede enc } \\
\text { agua dulce, que co } \\
\text { más consumidas po }\end{array}$ \\
\hline \multicolumn{5}{|c|}{ Figura 3. Estofado de Campeche. } \\
\hline & 2 & -5 & & $\sqrt{\frac{1}{2}}$ \\
\hline
\end{tabular}

Fuente: (GAD La Maná, 2013)

\begin{tabular}{|c|c|c|c|l|}
\hline & & & $\begin{array}{l}\text { El hornado dentro de Pucayacu es un plato típico } \\
\text { muy apetecido por todos, por su peculiar } \\
\text { combinación de sabores como es el chancho } \\
\text { hornado, la tortilla de papa, mote y su infaltable } \\
\text { ensalada, este platillo es muy apetecible por los } \\
\text { pobladores y visitantes. }\end{array}$ \\
\hline
\end{tabular}

Figura 4. Hornado.

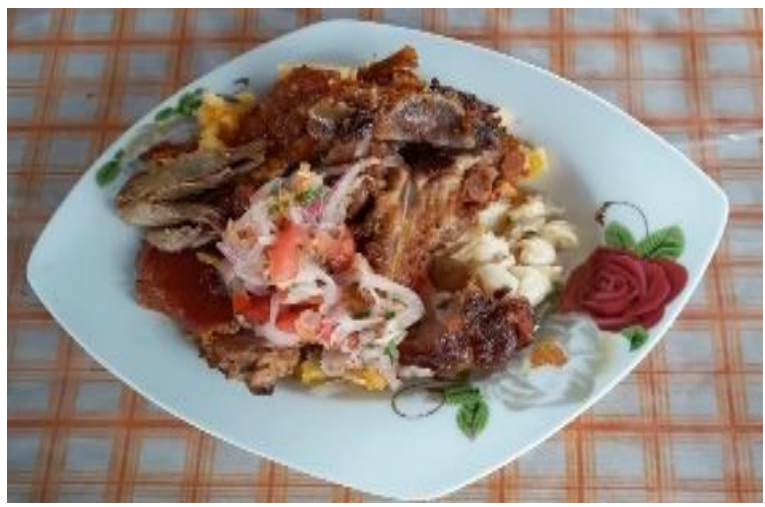

Fuente: (Castillo Laura, 2020)

Tabla $N^{\circ}$ 3: Inventario Cultural. 


\begin{tabular}{|c|c|c|c|c|}
\hline Denominación & Tipo & Sub tipo & Parroquia & Descripción \\
\hline $\begin{array}{c}\text { Carnaval de la } \\
\text { Alegría y el } \\
\text { Folklor } \\
\text { Lamanense }\end{array}$ & Fiestas & Carnaval & La Maná & $\begin{array}{l}\text { El carnaval se inicia en la administración del Ing. Rodrigo } \\
\text { Armas, quien tuvo la idea de formar un comité del carnaval } \\
\text { con varias instituciones, tanto del sector público como del } \\
\text { sector privado; es decir, el municipio, la policía, comisaría } \\
\text { nacional jefatura política, los medios de comunicación } \\
\text { como radio fantástica, y además algunos ciudadanos } \\
\text { célebres de aquí del cantón. }\end{array}$ \\
\hline
\end{tabular}

Figura 5. Carnaval de la Alegría y el Folclor.

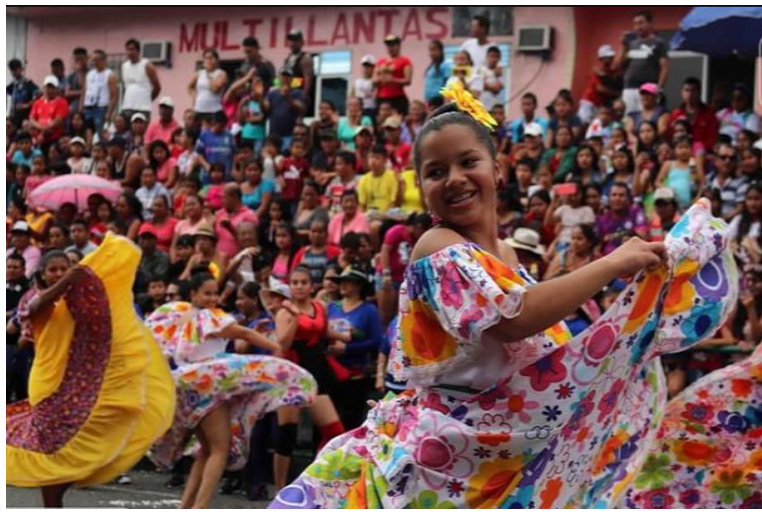

Fuente: (GAD La Maná, 2019)

\begin{tabular}{|c|c|c|c|c|}
\hline $\begin{array}{l}\text { Día de los } \\
\text { Difuntos }\end{array}$ & Fiestas & $\begin{array}{c}\text { Fiestas } \\
\text { Religiosas }\end{array}$ & La Maná & $\begin{array}{l}\text { Para los lamanenses el } 2 \text { de noviembre es una fecha de gran } \\
\text { importancia se refiere a la costumbre de las personas que } \\
\text { han perdido a sus seres queridos en ir al cementerio días } \\
\text { previos a esta fecha para arreglar la fachada de las tumbas, } \\
\text { los familiares se reúnen ahí durante varias horas para } \\
\text { realizar limpieza, mientras unos lijan otros colocan adornos, } \\
\text { alrededor las tumbas quedan arregladas para la víspera de la } \\
\text { fecha porque tiene como rutina acudir al cementerio } \\
\text { también el } 1 \text { de noviembre. }\end{array}$ \\
\hline
\end{tabular}

Figura 6. Día de los difuntos.

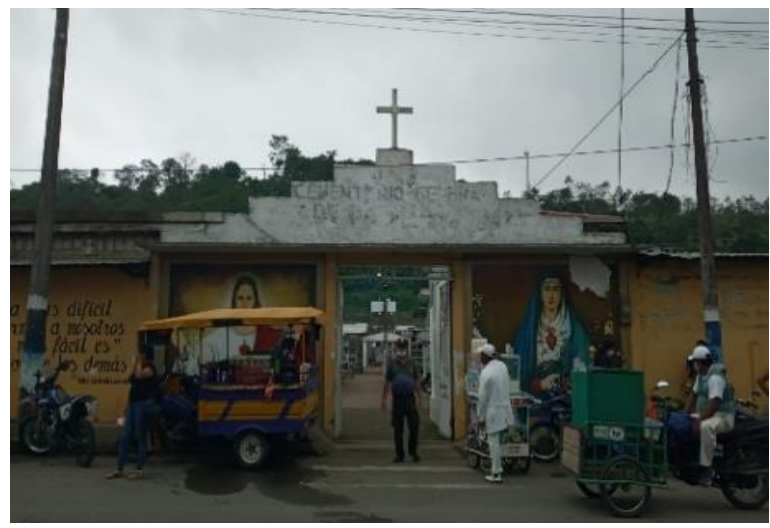

Fuente: (Castillo Laura, 2020)

Tabla $N^{\circ}$ 4: Inventario Cultural. 


\begin{tabular}{|c|c|c|c|l|}
\hline Denominación & Tipo & Sub tipo & Parroquia & \multicolumn{1}{c|}{ Descripción } \\
\hline $\begin{array}{c}\text { Elaboración de } \\
\text { Panela }\end{array}$ & Gastronomía & $\begin{array}{l}\text { En lo que respecta a la cocida del jugo de caña } \\
\text { utilizan varios términos para referirse al punto de } \\
\text { cocción en el que éste se encuentra. Luego de } \\
\text { dos horas de cocido a fuego alto, éste se alza } \\
\text { (ebulle), y para que ya no se alce, hay que poner } \\
\text { Tanteca". Una vez que se pone la manteca "el } \\
\text { caldo se asienta y de ahí hay que dejarlo a fuego } \\
\text { lento para que dé el punto. Luego hay que sacar } \\
\text { ala batea y mecer hasta que se seque para luego } \\
\text { ponerla en los jucos (moldes). }\end{array}$ \\
\hline
\end{tabular}

Figura 7. Elaboración de la panela.

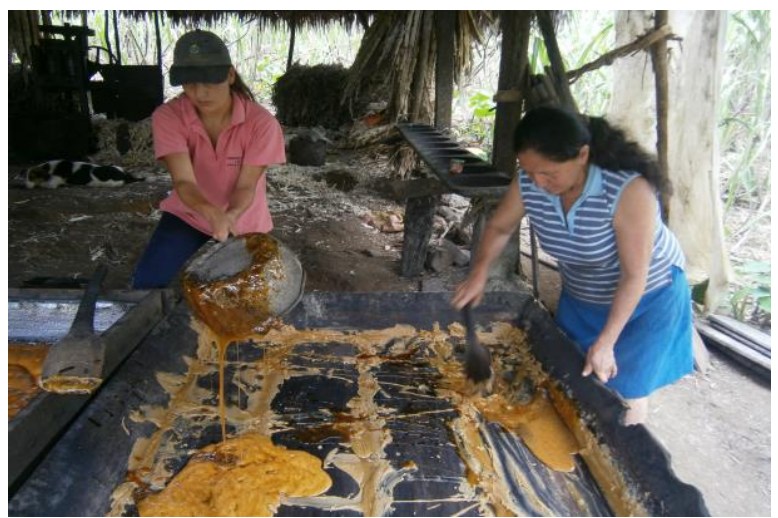

Fuente: (GAD La Maná, 2013)

\begin{tabular}{|c|c|c|c|c|}
\hline $\begin{array}{c}\text { Festividad } 19 \text { de } \\
\text { mayo - } \\
\text { Cantonización } \\
\text { de La Maná }\end{array}$ & Fiestas & $\begin{array}{c}\text { Fiesta } \\
\text { Cantonización }\end{array}$ & La Maná & $\begin{array}{l}\text { El } 19 \text { de mayo de } 1986 \text { el poblado La Maná logra } \\
\text { su anhelada cantonización, el patriotismo de los } \\
\text { habitantes de la parroquia junto a sus anhelos de } \\
\text { futuro, no se detuvo jamás y no se detendrá. Los } \\
\text { habitantes de este bello cantón tienen un espíritu } \\
\text { de sacrificio y un empuje imbatible para alcanzar } \\
\text { logros que beneficien al terruño tan querido para } \\
\text { toda su gente. }\end{array}$ \\
\hline
\end{tabular}

Figura 8. Festividad 19 de mayo- Cantonización de La Maná.

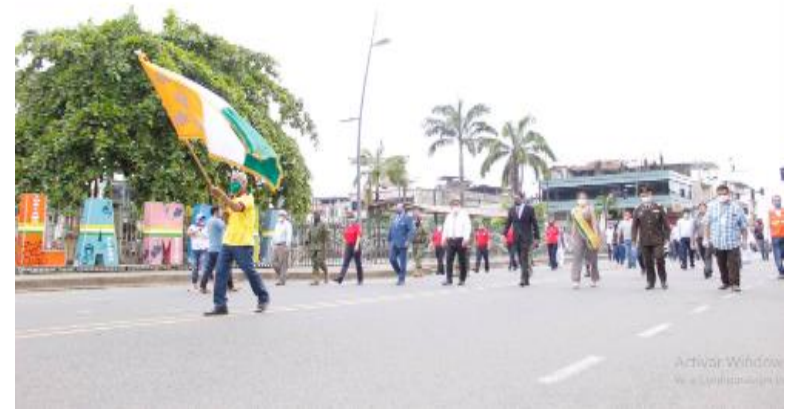

Fuente: (GAD La Maná, 2020)

Tabla $N^{\circ}$ : Inventario Cultural. 


\begin{tabular}{|c|c|c|c|c|}
\hline Denominación & Tipo & Sub tipo & Parroquia & \multicolumn{1}{c|}{ Descripción } \\
\hline $\begin{array}{c}\text { Fiestas Virgen } \\
\text { del Carmen }\end{array}$ & Fiestas & $\begin{array}{l}\text { Fiestas } \\
\text { Religiosas }\end{array}$ & El Carmen de la Virgen del Carmen se realiza el 16 \\
& & $\begin{array}{l}\text { Le julio de cada año, los priostes se escoge por el } \\
\text { padre o párroco y de igual manera se escoge la } \\
\text { persona que es saliente de prioste, en estas fiestas } \\
\text { son extensas ya que cuenta con la novena, y de ahí } \\
\text { dos días más para las fiestas de la Virgen, realizan } \\
\text { juegos tradicionales para niños y niñas de igual } \\
\text { forma para hombres y mujeres en esta parroquia se } \\
\text { evidencia la igualdad de género en todo sentido. }\end{array}$ \\
\hline
\end{tabular}

Figura 9. Fiestas Virgen del Carmen.

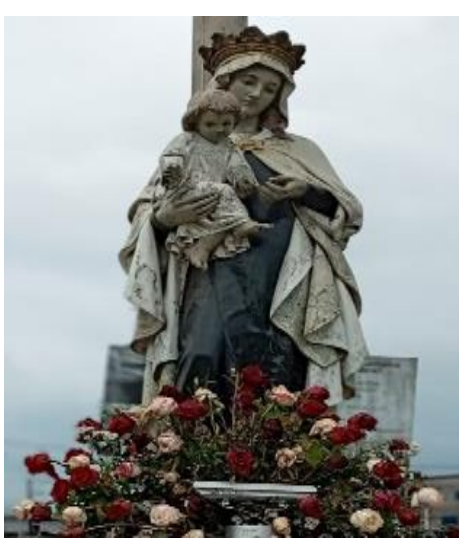

Fuente: (Chango Mishel, 2020)

\begin{tabular}{|c|c|c|c|c|}
\hline $\begin{array}{l}\text { Historia de la } \\
\text { Casa de la } \\
\text { Cultura de La } \\
\text { Maná }\end{array}$ & $\begin{array}{c}\text { Manifestaciones } \\
\text { Religiosas y } \\
\text { Creencias } \\
\text { Populares }\end{array}$ & Literatura & La Maná & $\begin{array}{l}\text { Jorge Villarreal destaca el apoyo de muchos } \\
\text { ciudadanos e instituciones, principalmente de la } \\
\text { UNE la Maná, la liga deportiva cantonal y el } \\
\text { colegio } 19 \text { de mayo que facilitan las instalaciones } \\
\text { para los repaso; en este primer año la casa de la } \\
\text { cultura se ha convertido en la impulsora del arte, } \\
\text { no solo en la ciudad sino también en la región, } \\
\text { participando en diferentes eventos como el } \\
\text { carnaval cultural, organizando el concurso de body } \\
\text { paint y participando del desfile folclor, así mismo } \\
\text { participando en la Ronda folclórica del cantón La } \\
\text { Maná. }\end{array}$ \\
\hline
\end{tabular}

Figura 10. Festividad 19 de mayo- Cantonización de La Maná.

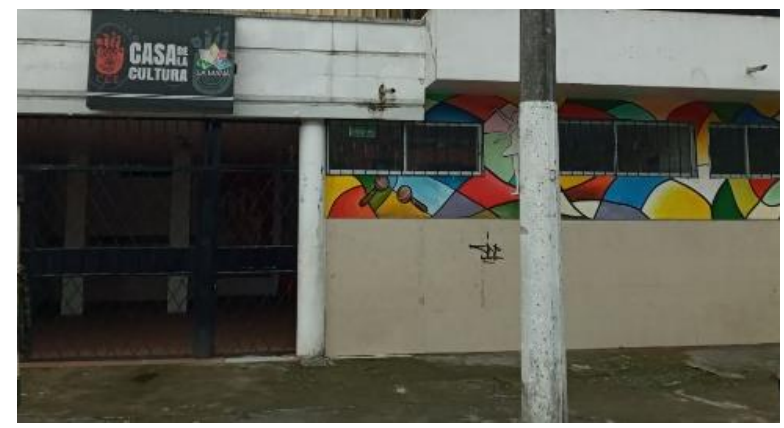

Fuente: (Castillo Laura, 2020)

Tabla N $^{\circ}$ 6: Inventario Cultural. 


\begin{tabular}{|c|c|c|c|c|}
\hline Denominación & Tipo & Sub tipo & Parroquia & Descripción \\
\hline $\begin{array}{l}\text { Historia del } \\
\text { Ingeniero } \\
\text { Sotomayor }\end{array}$ & $\begin{array}{c}\text { Manifestaciones } \\
\text { Religiosas y } \\
\text { Creencias } \\
\text { Populares }\end{array}$ & Literatura & La Maná & $\begin{array}{l}\text { Elías Guillermo Sotomayor Navas nació el } 19 \text { de } \\
\text { Septiembre de } 1924 \text { en Quevedo y fallece en el } \\
2005 \text {, sin embargo su huella histórica ha } \\
\text { trascendido hasta el día de hoy, Fue un amante a } \\
\text { la investigación, de ellas el descubrimiento del } \\
\text { oro líquido, presente en grandes proporciones en } \\
\text { el agua de La Maná, los relatos sobre la } \\
\text { existencia de pirámides en los puntos } \\
\text { electromagnéticos del mundo, así como sus } \\
\text { narraciones acerca de sus encuentros con extra } \\
\text { terrestres, debido a que ellos venían a recargar a } \\
\text { sus platillos voladores del agua de La Maná }\end{array}$ \\
\hline
\end{tabular}

Figura 11. Ing. Sotomayor.

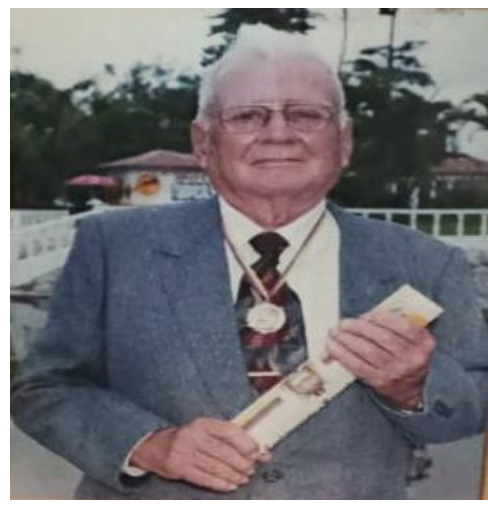

Fuente: (Sotomayor Alegría, 2020)

\begin{tabular}{|c|c|c|c|c|}
\hline $\begin{array}{l}\text { Historia sobre } \\
\text { Carlos Lozada }\end{array}$ & $\begin{array}{c}\text { Manifestaciones } \\
\text { Religiosas y } \\
\text { Creencias } \\
\text { Populares }\end{array}$ & Literatura & La Maná & $\begin{array}{l}\text { Carlos Lozada Quintana fue oriundo de Pujilí y } \\
\text { por cuestiones del destino sus padres decidieron } \\
\text { viajar hacia la zona costera así trabajaron como } \\
\text { cuidadores en la hacienda de la familia Arcos } \\
\text { luego de varios años le ofrecieron vender unos } \\
\text { terrenos, donde él trabajaba es así como se } \\
\text { compraron estas hermosas tierras con su grande } \\
\text { amigo Gonzalo y luego se repartieron los } \\
\text { terrenos. }\end{array}$ \\
\hline
\end{tabular}

Figura 12. Carlos Lozada.

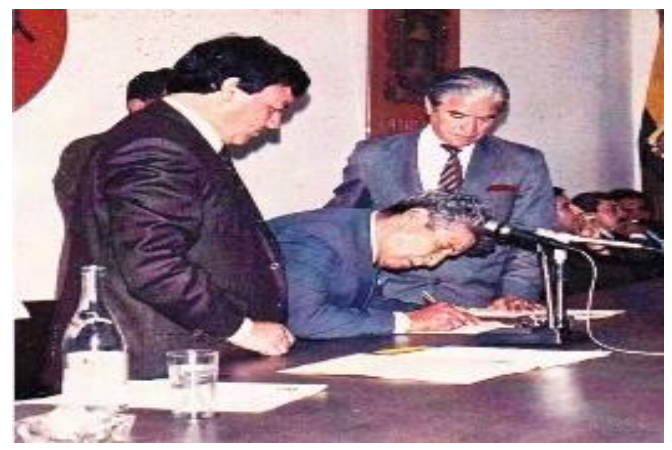

Fuente: (GAD La Maná, 2020)

Tabla $N^{\circ} 7$ : Inventario Cultural. 


\begin{tabular}{|c|c|c|c|c|}
\hline Denominación & Tipo & Sub tipo & Parroquia & Descripción \\
\hline $\begin{array}{l}\text { Leyenda de Don } \\
\text { Montaño }\end{array}$ & $\begin{array}{c}\text { Manifestaciones } \\
\text { Religiosas y } \\
\text { Creencias } \\
\text { Populares }\end{array}$ & Leyendas & La Maná & $\begin{array}{l}\text { Montaño un cuento vivo es una leyenda por los } \\
\text { años 1955-1980 del siglo pasado, cuando todo } \\
\text { era diferente a lo que es hoy, sin luz eléctrica, } \\
\text { sin radio, sin agua ni siquiera entubada, las } \\
\text { personas que vivían en esa época se } \\
\text { conformaban con diversiones sencillas y sanas. } \\
\text { En ese tiempo en este pueblo vivía un señor } \\
\text { muy simpático e inteligente para inventarse } \\
\text { chistes y anécdotas muy curiosos con los cuales } \\
\text { entretenía por las tardes a sus amigos. }\end{array}$ \\
\hline
\end{tabular}

Figura 13. Leyenda de Don Montaño.

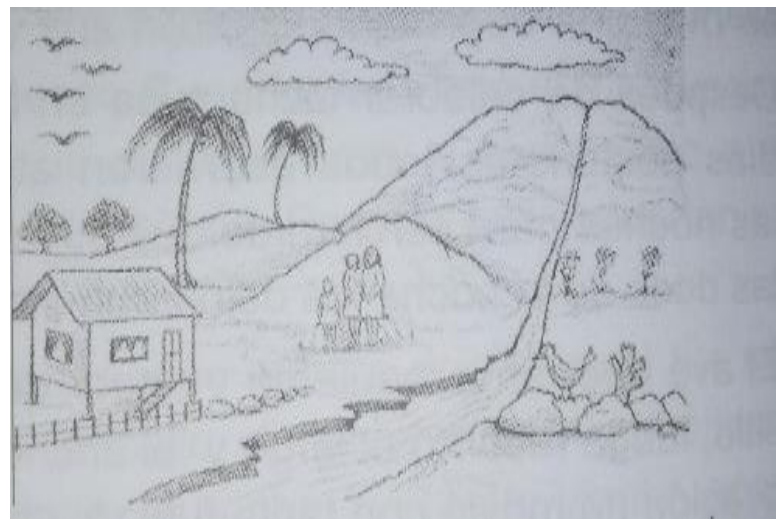

Fuente: (La Maná tierra fecunda, 2017)

\begin{tabular}{|c|c|c|c|c|}
\hline $\begin{array}{c}\text { Leyenda de la } \\
\text { Loma Del } \\
\text { Tesoro }\end{array}$ & $\begin{array}{c}\text { Manifestaciones } \\
\text { Religiosas y } \\
\text { Creencias } \\
\text { Populares }\end{array}$ & Leyendas & Guasaganda & $\begin{array}{l}\text { Para cruzar a Guasaganda existía un camino de } \\
\text { herradura que se desarrolló por la loma y cuenta } \\
\text { la leyenda que las personas descansaban en el } \\
\text { sitio de la planicie y que según en las noches } \\
\text { aparecía una llama azulada que indicaba la } \\
\text { presencia de un tesoro en aquel lugar. }\end{array}$ \\
\hline
\end{tabular}

Figura 14. Carlos Lozada.

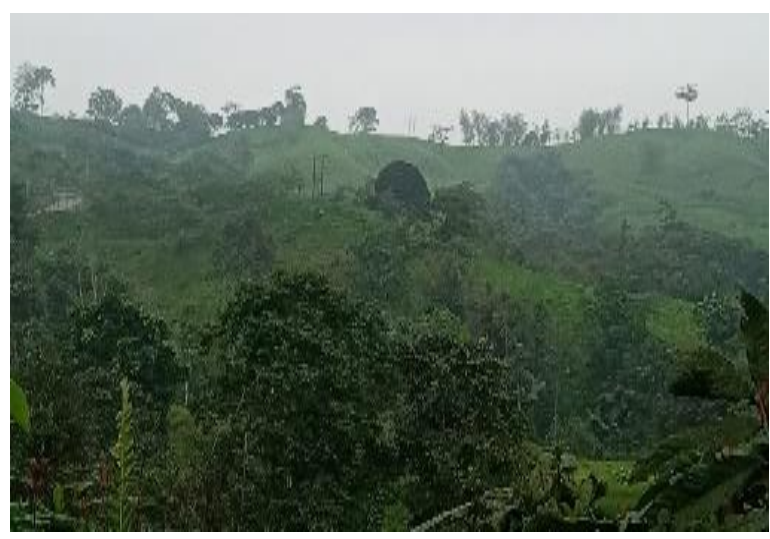

Fuente: (GAD La Maná, 2020)

Tabla $N^{\circ}$ 8: Inventario Cultural. 


\begin{tabular}{|c|c|c|c|c|}
\hline Denominación & Tipo & Sub tipo & Parroquia & Descripción \\
\hline $\begin{array}{c}\text { Leyendas de la } \\
\text { Vuelta o Curva } \\
\text { del Diablo }\end{array}$ & $\begin{array}{c}\text { Manifestaciones } \\
\text { Religiosas y } \\
\text { Creencias } \\
\text { Populares }\end{array}$ & Leyendas & Pucayacu & $\begin{array}{l}\text { Hace } 52 \text { años atrás en la curva existía muchos } \\
\text { accidentes que causó la muerte de varias } \\
\text { personas e incluso animales, lo cual ocurrió } \\
\text { algunos sucesos, cerca de la vuelta existían } \\
\text { unas viviendas las cuales comentaban que se } \\
\text { escuchaban pasos e incluso se veía un bulto } \\
\text { blanco, pero se desvanecía instantáneamente, } \\
\text { esto sucedía pasado la media noche. }\end{array}$ \\
\hline
\end{tabular}

Figura 15. Vuelta o curva del diablo.

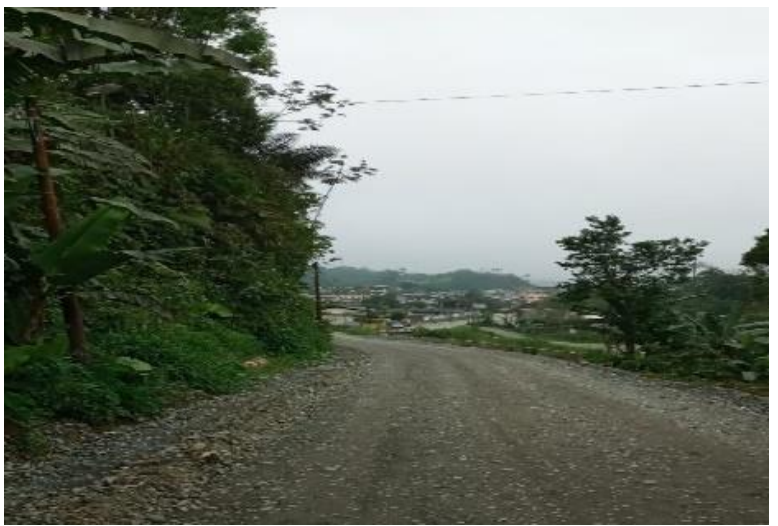

Fuente: (Chango Mishel, 2020)

\begin{tabular}{|c|l|l|l|l|}
\hline $\begin{array}{c}\text { Mes de la } \\
\text { Cultura y las } \\
\text { Artes }\end{array}$ & Fiestas & $\begin{array}{c}\text { Fiesta del } \\
\text { Mes de la } \\
\text { Cultura y } \\
\text { las Artes }\end{array}$ & La Maná & $\begin{array}{l}\text { Jorge Villareal fue quien encabezo El mes de la } \\
\text { cultura padre Carlos Jiménez le pusieron el } \\
\text { nombre del párroco pues en vista de que tenía } \\
\text { gran poder de convencimiento a los jóvenes y } \\
\text { ayudaba a impulsar la cultura, la política, esto } \\
\text { se realiza cada agosto. }\end{array}$ \\
\hline
\end{tabular}

Figura 16. Mes de la cultura y las artes.

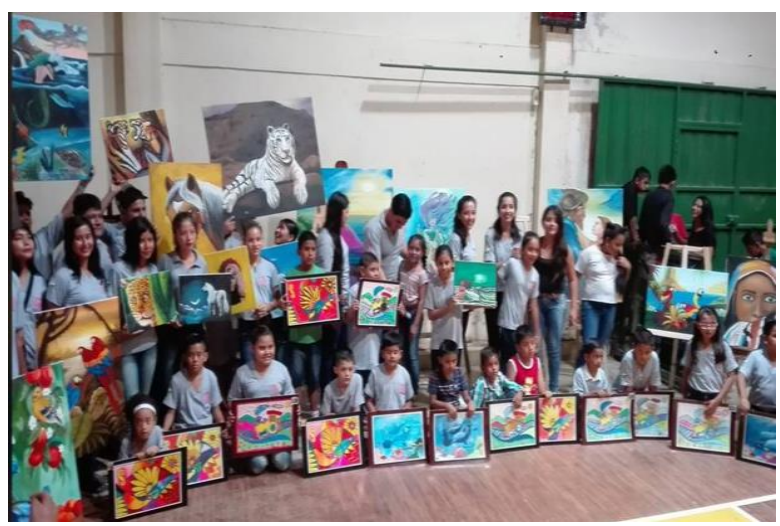

Fuente: (GAD La Maná, 2019)

Tabla N9: Inventario Cultural. 


\begin{tabular}{|c|c|c|c|c|}
\hline Denominación & Tipo & Sub tipo & $\begin{array}{c}\text { Parroqu } \\
\text { ia }\end{array}$ & Descripción \\
\hline $\begin{array}{c}\text { Piezas } \\
\text { arqueológicas } \\
\text { que reposan en } \\
\text { el Municipio La } \\
\text { Maná }\end{array}$ & Histórica & $\begin{array}{c}\text { Sitio } \\
\text { Arqueológico }\end{array}$ & La Maná & $\begin{array}{l}\text { Objetos arqueológicos que forman parte de la } \\
\text { colección, producto de la investigación } \\
\text { arqueológica. En el periodo formativo se obtuvo la } \\
\text { cultura Valdivia (1700 - } 1440 \text { A.C.), Cultura } \\
\text { Chorrera (1440-820 A.C.), en el periodo de } \\
\text { desarrollo regional tenemos la cultura Guangala } \\
\text { (658 - } 977 \text { A.C), Cultura Tejar Daule (658 - } 977 \\
\text { A.C), en el periodo integración trabajaron el } \\
\text { proyecto cadena Quevedo - La Maná teniendo el } \\
\text { asentamiento de aborígenes de la cultura Milagro } \\
\text { Quevedo Tsáchilas ( } 1300 \text { - } 1530 \text { D.C.) }\end{array}$ \\
\hline
\end{tabular}

Figura 17. Piezas arqueológicas.

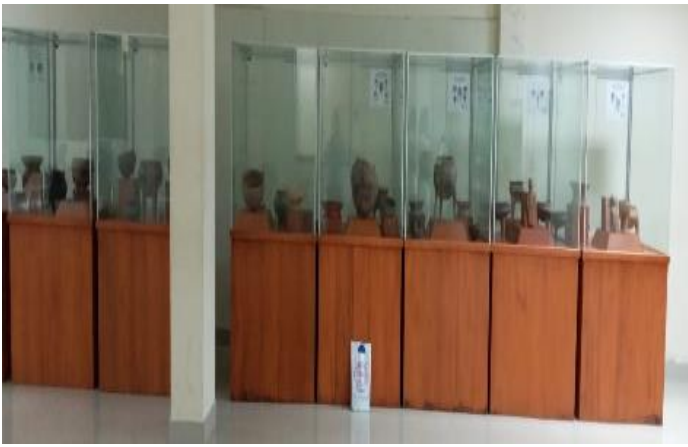

Fuente: (Chango Mishel, 2020)

\begin{tabular}{|c|c|c|c|c|}
\hline $\begin{array}{c}\text { Relatos Sobre } \\
\text { Ovnis }\end{array}$ & $\begin{array}{c}\text { Manifestaciones } \\
\text { Religiosas y } \\
\text { Creencias } \\
\text { Populares }\end{array}$ & Mitos & La Maná & $\begin{array}{l}\text { Don Guillermo Sotomayor compro tierras en lo alto } \\
\text { de las Montañas teniendo el claro objetivo de extraer } \\
\text { oro, pero a raíz de varias excavaciones fue } \\
\text { encontrado artefactos de piedra con diferentes } \\
\text { diseños, por ello el dejo de excavar y entendió que } \\
\text { se encuentra dentro del punto más energético del } \\
\text { planeta, lo que más le llamo la atención fue una } \\
\text { figura que encontró en forma de una pirámide en su } \\
\text { punta un ojo que brillaba. }\end{array}$ \\
\hline
\end{tabular}

Figura 18. Relatos sobre ovnis.

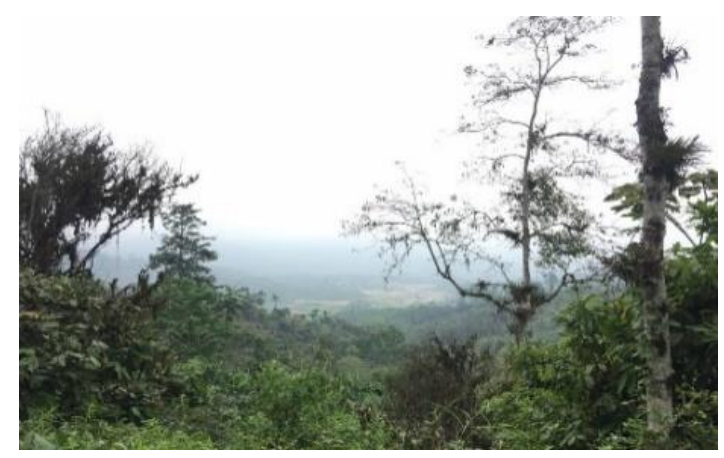

Fuente: (Chango Mishel, 2020)

Tabla $\mathrm{N}^{\circ}$ 10: Inventario Cultural. 


\begin{tabular}{|c|c|c|c|c|}
\hline Denominación & Tipo & Sub tipo & Parroquia & Descripción \\
\hline $\begin{array}{c}\text { Reseña } \\
\text { Histórica de La } \\
\text { Maná }\end{array}$ & $\begin{array}{c}\text { Manifestaciones } \\
\text { Religiosas y } \\
\text { Creencias } \\
\text { Populares }\end{array}$ & Literatura & La Maná & $\begin{array}{l}\text { La Maná se desarrolló sobre las ruinas de una } \\
\text { cultura que apenas se conocen sus vestigios, } \\
\text { tradiciones y más que estos testimonios } \\
\text { arqueológicos, que no están codificadas } \\
\text { oficialmente que han sido descubiertos o } \\
\text { encontrados en forma casual con la gente que } \\
\text { como siempre laboraba su tierra buscando su } \\
\text { futuro en la siembra de sus productos como la } \\
\text { yuca, el café, el cacao, descubren testimonios que } \\
\text { confirman la existencia de ecuatorianos que } \\
\text { hicieron su vida, su pueblo en esta tierra. } \\
\text { (Alarcón, 1996) }\end{array}$ \\
\hline
\end{tabular}

Figura 19. Reseña Histórica de La Maná.

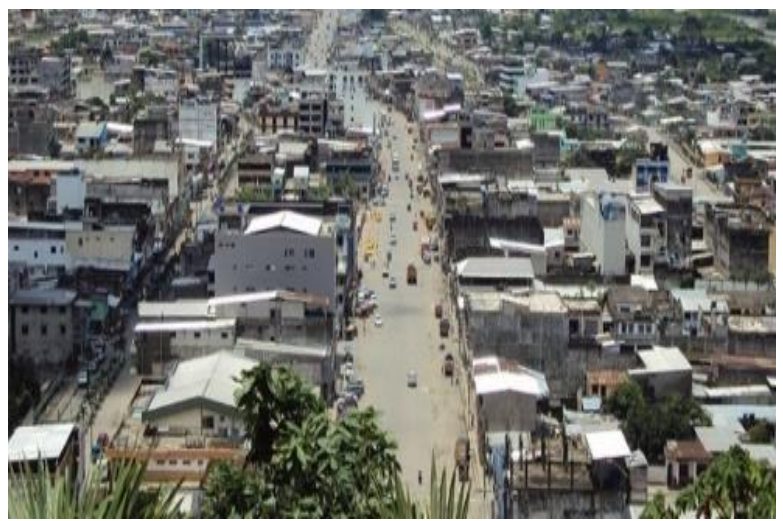

Fuente: (GAD La Maná, 2013)

\section{Conclusiones.}

- Se analizó la recopilación de información en campo de todos los bienes tangibles e intangibles que existen en el cantón La Maná, se constató que las personas más longevas de cada parroquia son las que llevan todos los conocimientos de la historia y la cultura que representa en cada zona, esto es importante ya que se espera que se siga difundiendo en las generaciones actuales y futuras por el hecho de se puede aprovechar estas fortalezas como una entrada a la economía del cantón, incrementando visitantes amantes a la cultura viva que posee la tierra Lamanense.

- Los bienes culturales son fundamentales en la investigación en los cuales se estableció a cada bien en su ámbito correspondiente, se tomó como referencia al instructivo para fichas de registro e inventario patrimonio cultural inmaterial del INPC, en el cual se pudo evidenciar 5 ámbitos que se clasifican de la siguiente manera, como las tradiciones y expresiones orales, artes del espectáculo, usos sociales, rituales y actos festivos, conocimientos y usos relacionados con la naturaleza y el universo y técnicas artesanales tradicionales y registro e inventario de bienes arqueológicos con la ficha de registro de colecciones arqueológicas. 
- Se pudo constatar que por medio de las encuestas realizadas a los habitantes y turistas del cantón la necesidad de elaborar el inventario cultural con el propósito de fomentar el turismo local, de tal manera que se aportara con información necesaria de las diferentes manifestaciones culturales del cantón La Maná

- El inventario cultural realizado en el Cantón La Maná dio como resultado a 58 manifestaciones culturales las cuales corresponden a los 5 ámbitos del patrimonio cultural inmaterial y 1 de bienes muebles, se brinda a la ciudadanía la correcta información, con ayuda del GAD Municipal se subirá a Sistema de información del Patrimonio Cultural Ecuatoriano (SIPCE), con esto se podrá tener el decido presupuesto para cada uno de las manifestaciones culturales consiguiente a la promoción de cada uno.

\section{Referencias bibliográficas.}

Alarcón, L. (1996). La Maná de la Nagación a la Afirmación. La Maná. Recuperado el 04 de Noviembre de 2020

Camelo, D. (2013). Programa Nacional de Inventario del Patrimonio Cultural. Recuperado el 20 de Noviembre de 2020, de https://mincultura.gov.co/areas/patrimonio/investigacion-ydocumentacion/programa-de-inventario-y-registro-del-patrimoniocultural/Paginas/default.aspx\#: :text=Los\%20inventarios\%20de\%20patrimonio\% 20 cultu ral,de\%20las\%20comunidades\%20y\%20colectividades

INPC. (2011). Istructivo para fichas de registro e inventario Patrimonio Cultural Inmaterial. Recuperado el 20 de Noviembre de 2020, de https://downloads.arqueoecuatoriana.ec/ayhpwxgv/noticias/publicaciones/INPC-XInstructivoParaFichasDeRegistroInventarioPatrimonioInmaterial.pdf

INPC. (s.f.). Sistema de Información del Patrimonio Cultural Ecuatoriano (SIPCE). Recuperado el 20 de Noviembre de 2020, de https://www.patrimoniocultural.gob.ec/sistema-deinformacion-del-patrimonio-cultural-ecuatoriano-sipce/

Marias. (1949). El método histórico de las generaciones. Revista de Occidente, 169 - 178. Recuperado el 20 de Noviembre de 2020, de cervantesvirtual.com.

Marroquín, R. (2012). Universidad Nacional de Educación. Recuperado el 20 de Noviembre de 2020, de http://www.une.edu.pe/Sesion04-Metodologia_de_la_investigacion.pdf

Murray R. Spiegel y Larry J. Stephens. (2009). Estadística. 4ta edición. Mc Graw-Hill. México, D.F. Recuperado el 20 de Noviembre de 2020

Pacheco, J. (15 de 08 de 2019). Web y Empresa. Recuperado el 20 de Noviembre de 2020, de https://www.webyempresas.com/metodo-sintetico/ 
PDOT. (2015 - 2020). Plan de Desarrollo y Ordenamiento Territorial del Cantón Maná. Recuperado el 20 de Noviembre de 2020, de http://app.sni.gob.ec/snilink/sni/PORTAL_SNI/data_sigad_plus/sigadplusdocumentofinal/0560000890001_Pdyot \%20La\%20Man\%C3\%A1\%202015_22-03-2016_16-42-48.pdf

Reinoso, L. (06 de Agosto de 2019). La Primicia. Recuperado el 20 de Noviembre de 2020, de https://laprimicia.ec/2019/08/06/cultura-viva-en-cotopaxi/

UNESCO. (02 de Noviembre de 2001). Organización de las Naciones Unidas para la Educación la Ciencia y la Cultura. Recuperado el 20 de Noviembre de 2020, de http://portal.unesco.org/es/ev.php-

URL_ID=13179\&URL_DO=DO_TOPIC\&URL_SECTION=201.html

UNESCO. (2019). Organización de las Naciones Unidas para la Educación la Ciencia y la Cultura. Recuperado el 20 de Noviembre de 2020, de https://es.unesco.org/themes/proteger-patrimonio-y-fomentar-creatividad

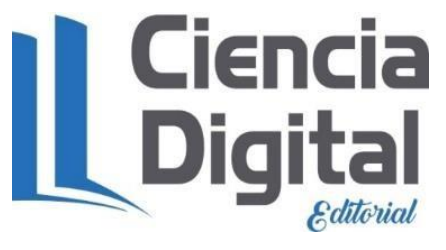


PARA CITAR EL ARTÍCULO INDEXADO.

Castillo Oviedo, L. M., Chango Tenelema, M. del R., \& Zambrano Cuadro, N. G. (2021). Inventario cultural tangible e intangible del cantón La Maná provincia de Cotopaxi año 2020. Ciencia Digital, 5(1), 30-50. https://doi.org/10.33262/cienciadigital.v5i1.1517

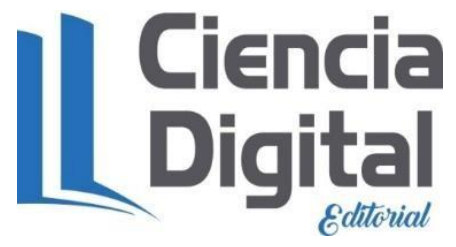

El artículo que se publica es de exclusiva responsabilidad de los autores y no necesariamente reflejan el pensamiento de la Revista Ciencia Digital.

El artículo queda en propiedad de la revista y, por tanto, su publicación parcial y/o total en otro medio tiene que ser autorizado por el director de la Revista Ciencia Digital.
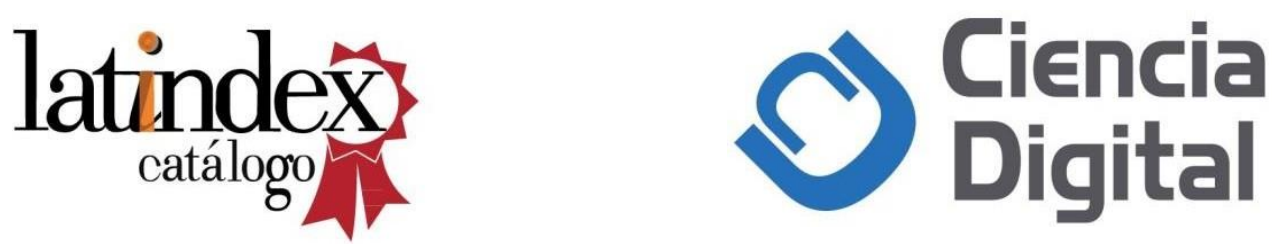